\title{
A carotid web as a rare cause of ischaemic stroke: a case report
}

\author{
Authors: Uwais Dudhiya, ${ }^{\mathrm{A}}$ Valerious Poliditis, ${ }^{\mathrm{B}}$ Doreen $\mathrm{Ko}^{\mathrm{A}}$ and Anil Agarwal ${ }^{\mathrm{A}}$
}

\section{Background}

A carotid web is a shelf-like filling defect projecting from the lumen of the carotid artery. ${ }^{1}$ An internal carotid artery carotid web was first described as a cause of ischaemic stroke in 1967 by Ehrenfield et $a .^{2}$ Carotid webs are particularly associated with recurrent ipsilateral strokes as it is a location for turbulent flow leading to stasis and thrombus formation. 3,4

\section{Case report}

We present the case of a 49 -year-old gentleman who was admitted with sudden onset left-sided weakness and speech difficulties. On examination this gentleman had left-sided hemiplegia, left-sided hemispatial neglect, dysarthria and left-sided hemianopia.

The computed tomography (CT) of the head described the presence of a hyperdensity in the branches of the middle cerebral artery (MCA), one of the earliest signs of a thrombus in the cerebral vasculature. ${ }^{5}$ The patient subsequently had a CT angiogram (CTA) which showed an occlusion of the right MCA. The CTA also revealed the presence of an intraluminal, shelf-like projection arising from the posterior wall of the right internal carotid artery, located just above the carotid bifurcation, causing $65 \%$ stenosis. This finding was diagnostic of a carotid web.

The patient was subsequently thrombolysed and was transferred to a tertiary centre for thrombectomy. The patient then had a carotid stent inserted - one of the many interventions for a carotid web for secondary prevention. Following the treatment, our patient made a complete recovery and had a good 3-month follow up.

\section{Discussion}

A carotid web is a relatively rare and often under-diagnosed cause of embolic stroke. ${ }^{6}$ This case report describes the importance of diagnosing a carotid web as the cause of ischaemic stroke as management for this varies to other more common causes of ischaemic stroke. Investigating for carotid web remains difficult as the differential diagnosis of a carotid web on imaging include vascular dissection, focal atherosclerotic plaque and post-traumatic aneurysm. ${ }^{6}$ Diagnosis using carotid ultrasound has been shown to be difficult with previous cases reporting poor differentiation

Authors: ${ }^{A}$ Basildon University Hospital, Basildon, Essex, UK; ${ }^{B}$ Mid Essex Hospital Services NHS Trust, Essex, UK between plaques and carotid webs. ${ }^{3,4}$ The best non-invasive imaging modality to date is a CTA. ${ }^{?}$

Treatment for carotid web remains a dilemma - many cases have reported recurrent embolic events while on antiplatelet therapy, ${ }^{1,7,8}$ while some cases have been reported to have been medically managed with dual antiplatelet therapy with good 6-month follow up. ${ }^{6}$ The placement of a carotid stent has been proposed as a good alternative therapeutic option, with previous literature documenting good 4 -year follow up. ${ }^{9}$ A high index of suspicion for a carotid web is required especially for patients with minimal risk factors who develop a stroke, as managing the condition can potentially prevent fatal complications.

\section{Conflict of interest statement}

None declared.

\section{References}

1 Choi PM, Singh D, Trivedi A et al. Carotid webs and recurrent ischemic strokes in the era of CT angiography. AJNR Am J Neuroradiol 2015;36:2134-9.

2 Ehrenfeld WK, Stoney RJ, Wylie EJ. Fibromuscular hyperplasia of the internal carotid artery. Arch Surg 1967;95:284-7.

3 Joux J, Chausson N, Jeannin S et al. Carotid-bulb atypical fibromuscular dysplasia in young Afro-Caribbean patients with stroke. Stroke 2014:45:3711-3.

4 Antigüedad-Muñoz J, de la Riva P, Arenaza Choperena G et al. Internal carotid artery web as the cause of recurrent cryptogenic ischemic stroke. J Stroke Cerebrovasc Dis 2018;27:e86-7.

5 Abd Elkhalek YI, Elia RZ. Qualitative and quantitative value of hyperdense MCA sign as a prognostic marker for infarction. The Egyptian Journal of Radiology and Nuclear Medicine 2016; 47:1043-8.

6 Pacei F, Quilici L, Mullin S et al. Web of the carotid artery: An underrecognized cause of ischemic stroke. J Clin Neurosci 2018;50:122-3.

7 Osborn AG, Anderson RE. Angiographic spectrum of cervical and intracranial fibromuscular dysplasia. Stroke 1977;8:617-26.

8 Kubis N, Von Langsdorff D, Petitjean C et al. Thrombotic carotid megabulb: fibromuscular dysplasia, septae, and ischemic stroke. Neurology 1999;52:883-6.

9 Lenck S, Labeyrie MA, Saint-Maurice JP, Tarlov N, Houdart E. Diaphragms of the carotid and vertebral arteries: an under-diagnosed cause of ischaemic stroke. Eur J Neurol 2014;21;586-93. 